\title{
Seasonal changes on hydraulic conductance of mature olive trees under different water regimes
}

\author{
J.E. Fernández, A. Diaz-Espejo, \\ J.L. Muriel, R. Romero \\ J.M. Torres-Ruiz \\ IFAPA, Centro Las Torres-Tomejil \\ Instituto de Recursos Naturales y Agrobiología \\ Ctra. Sevilla-Cazalla, km 12.2 \\ IRNASE-CSIC \\ 41200-Alcalá del Río, Sevilla, Spain \\ Apartado 1052, 41080-Sevilla \\ Spain \\ A.Morales-Sillero, M.J. Martín-Palomo \\ Departamento de Ciencias Agroforestales, Universidad de Sevilla, 41013-Sevilla, Spain
}

Keywords: Olea europaea, sap flow, irrigation, transpiration, modelling

\begin{abstract}
The well know stomata control of olive trees under stressing conditions proved to be an efficient mechanism to prevent the loss of hydraulic efficiency during the dry season. Trees with a localized irrigation system that replaced $100 \%$ of the crop water demand (FAO trees), as well as Dryfarming trees, were able to keep similar differences between the water potential in the soil and that in the leaves, all throughout the dry season. The differences were of the same order than those in trees with non-limiting soil water conditions in the whole rootzone (Pond trees). As a consequence of stomatal closure, the tree transpiration late in the season was reduced in the FAO trees, but the hydraulic conductance remained unaffected. Results suggest that a root-to-shoot signalling mechanism could have been responsible for stomata control in the FAO trees. At the end of the dry season, values of hydraulic conductance were lower in Dryfarming than in the irrigated treatments, but, once again, the recorded leaf water potential values, when compared to vulnerability curves, suggest that the low hydraulic conductance in those trees was mainly due to a reduced tree transpiration caused by stomatal closure, rather than to a severe loss of the hydraulic efficiency.
\end{abstract}

\section{INTRODUCTION}

The olive tree shows an outstanding adaptation to drought (Fernández and Moreno, 1999). Among other mechanisms, the olive tree shows a reduction on the tree total transpiration $\left(E_{\mathrm{p}}\right)$ during the periods with high atmospheric demand (Tognetti et al., 2004), which helps to avoid values of water stress within the plant falling beyond the threshold for safe hydraulic functioning. Depending on the conditions, this reduction on $E_{\mathrm{p}}$ could be due just to a lack of water in the soil or to a marked stomatal control, which occurs in olive under conditions of high water stress (Fernández et al., 1997). The mentioned stomatal closure may be related to a root-to-shoot signalling mechanism occurring in trees with roots in drying soil. Fernández et al. (2003) used sap flow measurements to derive daily $E_{\mathrm{p}}$ values in mature 'Manzanilla' trees with a localized irrigation system that supplied enough water to replace the crop water demand $\left(\mathrm{ET}_{\mathrm{c}}\right)$. They observed an increase of $37 \%$ on $E_{\mathrm{p}}$ when the trees were suddenly irrigated with a pond irrigation that wetted the whole rootzone. The reduction on $E_{\mathrm{p}}$ may be also related to a reduction on the whole-tree hydraulic conductance $\left(K_{\mathrm{p}}\right)$, due to accumulation of xylem embolism during the dry season. The possible feedback loops or feed-forward regulations 
between the internal water status of the plant, $E_{\mathrm{p}}$ and $K_{\mathrm{p}}$ are not well known for the olive tree. Most the work concerning the hydraulic efficiency of the olive tree has been made with young trees growing in pots (Salleo and Lo Gullo, 1983; Nardini et al, 2006). To our knowledge, the only papers showing seasonal trends of $K_{\mathrm{p}}$ for mature olive trees growing in the field are those by Tognetti et al., $(2004,2005)$. The experimental trees were 11 and 12 -year-old 'Kalamata' olive trees growing in an area of sub-humid climate, with greater annual precipitation $(P)$ and lower atmospheric demand on the summer months than in most Mediterranean areas where the olive grows. Any new evidences on the mechanisms governing the seasonal trends both of $E_{\mathrm{p}}$ and $K_{\mathrm{p}}$ are of interest for improving deficit irrigation strategies, which are compulsory in most olive orchards (Fernández et al., 2003; Pastor, 2005).

The aim of this work was to investigate the seasonal trends of $K_{\mathrm{p}}$ in 39-year-old 'Manzanilla' olive trees growing under field conditions in a semi-arid area of south Spain. We wanted to know to what extent localized irrigation restricted $E_{\mathrm{p}}$ and $K_{\mathrm{p}}$, and whether any observed reduction on $K_{\mathrm{p}}$ was due to the lack of water in the soil or to other mechanisms such as those mentioned above.

\section{MATERIALS AND METHODS}

\section{Orchard characteristics and water treatments}

The experiments were made in a 0.5 ha olive orchard with 39-year-old 'Manzanilla de Sevilla' olive trees at $7 \mathrm{~m} \times 5 \mathrm{~m}$ spacing $\left(37^{\circ} 17^{\prime} \mathrm{N}, 6^{\circ} 3^{\prime} \mathrm{W}, 30 \mathrm{~m}\right.$ a.s.1.). The trees have a single trunk with two main branches from 0.7 to $1.5 \mathrm{~m}$ above ground. Average values of canopy volume and leaf area density at the end of the growing season were 42 $\mathrm{m}^{3}$ and $1.6 \mathrm{~m}^{2} \mathrm{~m}^{-3}$, respectively. The soil is a sandy loam of about $1.6-2.0 \mathrm{~m}$ depth, depending on the location. The texture is quite homogeneous, with average values of $14.8 \%$ clay, $7.0 \%$ silt, $4.7 \%$ fine sand and $73.5 \%$ coarse sand. The climate is typically Mediterranean, with a mild, wet season from October to April; the rest of the year is hot and dry. In 2007, the experimental year, precipitation $(P)$ and potential evapotranspiration (ET, FAO56 Penman-Monteith equation) were $411.1 \mathrm{~mm}$ and $1235.0 \mathrm{~mm}$, respectively.

The orchard is divided into three plots, each with a different water treatment: 1) Dryfarming, with rainfall as the only source of water supply; 2) FAO, in which trees were irrigated daily from May 14 to October 2, to replace the crop evapotranspiration $\left(\mathrm{ET}_{\mathrm{c}}\right.$, $\mathrm{mm})$. The irrigation system consisted of a lateral per tree row, with five $3 \mathrm{~L}^{\text {hour }}{ }^{-1}$ drippers per tree, $1 \mathrm{~m}$ apart. With this system some roots were left in drying soil. Irrigation doses were calculated with the crop coefficient approach, as described by Fernández et al. (2006a). Basically, $\mathrm{ET}_{\mathrm{c}}$ was calculated as $\mathrm{ET}_{\mathrm{c}}=K_{\mathrm{c}} K_{\mathrm{r}} \mathrm{ET}_{\mathrm{o}}$, with crop coefficient $\left(K_{\mathrm{c}}\right)$ values of 0.76 in May, 0.70 in June, 0.63 in July and August, 0.72 in September and 0.77 in October. The coefficient related to the percentage of ground covered by the crop $\left(K_{\mathrm{r}}\right)$ was $\left.0.71 ; 3\right)$ Pond, in which the trees were irrigated with a grid of pipes with a $2 \mathrm{~L}_{\text {hour }}{ }^{-1}$ dripper every $0.4 \mathrm{~m} \times 0.4 \mathrm{~m}$. The grid covered a surface of $8 \mathrm{~m}$ $\times 6 \mathrm{~m}$, with the tree in the middle, enough to keep non-limiting soil water conditions in the whole rootzone, all throughout the irrigation season.

\section{Determining the tree hydraulic conductance}

The $K_{\mathrm{p}}$ values were determined as $K_{\mathrm{p}}=E_{\mathrm{p}}\left(\Psi_{\mathrm{s}^{-}}-\Psi_{1}\right)^{-1}$, being $E_{\mathrm{p}}$ measured at the central hours of the day, when transpiration rates were relatively constant; $\Psi_{\mathrm{s}}(\mathrm{MPa})$ is the 'effective' soil water potential at the root surface and $\Psi_{1}(\mathrm{MPa})$ is the 'effective' leaf 
water potential for the whole canopy (Jones, 1983). Both $\Psi_{\text {s }}$ and $\Psi_{1}$ were determined at the same hours than $E_{\mathrm{p}}$. The values of $\Psi_{1}$ were estimated as $\Psi_{1}=\alpha \Psi_{\mathrm{o}}+(1-\alpha) \Psi_{\mathrm{i}}$ (Moreshet et al., 1990), where $\Psi_{\mathrm{o}}(\mathrm{MPa})$ is the leaf water potential of sunlit leaves outside the canopy, $\Psi_{\mathrm{i}}(\mathrm{MPa})$ is the leaf water potential of shade leaves inside the canopy, and $\alpha$ is the fraction of sunlit and shade leaves (calculated as 0.43 for the orchard conditions by Diaz-Espejo et

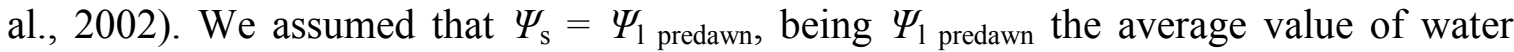
potential measured at predawn in leaves of the base of the trunk.

The values of $E_{\mathrm{p}}$ were determined from sap flow measurements made with the $\mathrm{Tz}$ compensation heat-pulse method (Green et al., 2003), calibrated for our orchard conditions by Fernández et al. (2006b). Three sets of probes were installed into the trunk of each two representative trees per treatment. Each probe had four thermocouples, at 5, 12, 22 and $35 \mathrm{~mm}$ below the cambium. Heat pulses (60 $\mathrm{W}$ over $1 \mathrm{~s}$ ) were applied every $30 \mathrm{~min}$. We were worried about not getting reliable estimations of $E_{\mathrm{p}}$ due to the high probe-to-probe variability caused by the irregular conductive tissue in such old trees. Therefore, we modelled the daily $E_{\mathrm{p}}$ values with the Penman-Monteith equation described by Moreno et al. (1996), improved with the $f$ functions for the leaf stomatal conductance $\left(g_{\mathrm{s}}\right)$ validated by Diaz-Espejo et al. (2006) for our orchard conditions. In addition, we derived average monthly $E_{\mathrm{p}}$ values in the orchard from the $\mathrm{ET}_{\mathrm{c}}$ values determined with the crop coefficient approach explained above, plus estimations of the water lost by evaporation from the soil surface, $E_{\mathrm{s}}$ (Fernández, 2006).

\section{Measurements}

Diurnal time courses of $\Psi_{\mathrm{o}}$ and $\Psi_{\mathrm{i}}$ were recorded on June 26 (day-of-year $=$ DOY $=$ $178)$, July $27(\mathrm{DOY}=206)$ and August $28(\mathrm{DOY}=241)$, i.e. from the time the treatments were well established to the end of the dry season. Each sampling day we measured both variables from predawn to sunset, every 2.5 hours (Scholander chamber). Every sampling hour we sampled 6 sunlit and 6 shade leaves per treatment ( 2 leaves per tree, 3 trees per treatment). The sampled leaves were the fourth or fifth from the apex of current year shoots at about 1.5-1.0 m above ground. Measurements of stomatal conductance $\left(g_{\mathrm{s}}\right)$ were made in the same type of leaves, at the same hours (Licor 6400, two leaves in three trees per treatment).

The volumetric soil water contents $(\theta)$ in the soil around three representative trees per treatment were measured every 7-10 days, at 0.1, 0.2, 0.3, 0.4, 0.6 and $1.0 \mathrm{~m}$ depth, and at 1,2 , and $3 \mathrm{~m}$ from the tree trunk (Profile probe). From the $\theta$ values we calculated the relative extractable water (REW) of the soil.

The leaf area (LA, $\mathrm{m}^{2}$ one side) of the trees in which $\theta$ was measured was estimated as described by Fernández et al. (2006a). We used those LA values as an input to the $E_{\mathrm{p}}$ model. Half-hour values of the main meteorological variables were continuously recorded by an automatic weather station next to the olive orchard.

Analyses of variance were performed on the data to compare the effect of the treatments on $\Psi_{1}, \Psi_{s}, E_{\mathrm{p}}$ and $K_{\mathrm{p}}$. Separation of means were obtained by the least significant differences (LSD) test.

\section{RESULTS AND DISCUSSION}

The imposed water conditions caused clear differences between treatments on the soil water status (Fig. 1a). The soil of the Pond trees was between saturation and field capacity most of the time, while that of the FAO trees remained close to field capacity. Under these conditions, similar values of $\Psi_{1}$ and $\Psi_{\mathrm{s}}$ were recorded in the trees of both treatments. 
The availability of soil water in the Dryfarming treatment was decreasing throughout the dry season, causing an increasing water stress both in the soil and in the trees (Fig. 1).

The dynamics of tree transpiration determined for each treatment from the sap flow records $\left(E_{\mathrm{p}-\mathrm{sf}}\right)$ echoed that of $\mathrm{ET}_{\mathrm{o}}$ (Fig. 2). The trends of $E_{\mathrm{p} \text {-sf }}$ were also consistent with the tree transpiration values estimated from the crop coefficient approach and estimations on soil water evaporation $\left(E_{\mathrm{p}-\mathrm{cc}}\right)$ : for the FAO treatment, values of $E_{\mathrm{p} \text {-sf }}$ and $E_{\mathrm{p} \text {-cc }}$ were quite similar, except on the periods of variable $\mathrm{ET}_{\mathrm{o}}$, because a single $E_{\mathrm{p}-\mathrm{cc}}$ value was calculated per month. For the Dryfarming treatment the $E_{\mathrm{p} \text {-sf }}$ values were usually lower than the estimated $E_{\mathrm{p}-\mathrm{cc}}$ value, as expected. For the pond treatment, the values of $E_{\mathrm{p} \text {-sf }}$ were above that of the $E_{\mathrm{p}-\mathrm{cc}}$, most of the time. This was also an expected result, because the $E_{\mathrm{p} \text {-cc }}$ values determined after Fernández et al (2006a) were validated for trees of the FAO treatment, which had lower soil water availability than the Pond trees (Fig. 1a). The agreement between the time courses of $E_{\mathrm{p} \text {-sf }}$ and those of the modeled tree transpiration $\left(E_{\mathrm{p}-\mathrm{m}}\right)$ were reasonably good, except for the Pond treatment, suggesting that the soil water routine included in the model need to be adjusted for ponding conditions. Results in Fig. 2 shows that the $E_{\mathrm{p} \text {-sf }}$ values were reliable and that we could use them with confidence to calculate $K_{\mathrm{p}}$.

Figure $3 \mathrm{a}$ shows that the olive trees were able to maintain the same value of $\Psi_{\mathrm{I}^{-}} \Psi_{\mathrm{s}}$ throughout the dry season. This was due, at least in part, to a reduction in $g_{\mathrm{s}}$ occurring in the less watered trees, observed in the sampling days of July and August. Thus, in the FAO trees the average maximum value of $g_{\mathrm{s}}$ recorded on August 28 was $0.177 \mathrm{~mol} \mathrm{~m}^{-2} \mathrm{~s}^{-}$ 1 , while $0.227 \mathrm{~mol} \mathrm{~m}^{-2} \mathrm{~s}^{-1}$ were recorded at the same time in the Pond trees. In the Dryfarming treatment, the maximum value of $g_{\mathrm{s}}$ recorded on that day was $0.092 \mathrm{~mol} \mathrm{~m}^{-2}$ $\mathrm{s}^{-1}$. This reduction in $g_{\mathrm{s}}$ may explain the lowest $E_{\mathrm{p}}$ values recorded in the FAO trees as compared to those of the Pond trees (Fig. 3b), and illustrates one of the well known adaptation mechanisms to drought in olive: the tree closes stomata to reduce $E_{\mathrm{p}}$ and thus to minimize the risk of the water potential in the xylem falling below the threshold for cavitation. In the Dryfarming treatment the $\Psi_{1}-\Psi_{\mathrm{s}}$ difference was also maintained throughout the dry season, but $E_{\mathrm{p}}$ decreased more than in the irrigated treatments (Fig. $3 a, b)$, probably because of the marked decrease in soil water availability (Fig. 1a).

Results on $\Psi_{\mathrm{o}}$ suggest that little reduction of the hydraulic efficiency could have been due to the appearance of embolism in the xylem vessels. In the FAO trees, the minimum $\Psi_{\mathrm{o}}$ value recorded during the experimental period was $-2.05 \mathrm{MPa}$ in July 24 . The vulnerability curves obtained for olive by Ennajeh et al. (2008) shows that that water stress value may cause a percentage loss of conductivity (PLC) below $20 \%$. Late in the season, the values of $K_{\mathrm{p}}$ in the FAO trees were, in fact, similar to those in Pond trees (Fig. $3 \mathrm{c}$ ). The Lowest $\Psi_{\mathrm{o}}$ values recorded in the Dryfarming trees (minimum $\Psi_{\mathrm{o}}$ average of -2.9 $\mathrm{MPa}$ on August 28) suggest PLC values little over those of the FAO trees. The smaller $K_{\mathrm{p}}$ values observed in that treatment late in the season, as compared to those of the irrigated trees, could have been due not only to the appearance of embolism in the xylem, but also, and perhaps mainly, to both the lack of water in the soil and the reduction in $g_{\mathrm{s}}$.

It seems, therefore, that the stomatal control of the olive trees was able to keep stress levels within the trees low enough to avoid a significant loss of hydraulic conductance within the plant. Now, the cause of such an efficient stomatal control remains unknown. The FAO trees surely had their roots under a wide range of soil water content, because of the heterogeneity of water distribution in the rootzone caused by the localized irrigation. Under those conditions, a root-to-shoot signalling mechanism could have been triggered. This agrees with observations by Fernández et al. (2003) in the same orchard. They 
observed a clear increase in $E_{\mathrm{p} \text {-sf }}$ in very few days after applying pond irrigation to dryfarming trees ( 7 days) and to trees previously under localized irrigation ( 2 days). This quick recover of $E_{\mathrm{p} \text {-sf }}$ suggests an increase on $g_{\mathrm{s}}$ as a response to the new soil water status, rather than a recovery of any possible damage to the conductive xylem caused by the appearance of embolism.

\section{ACKNOWLEDGEMENTS}

This work has been funded by the Spanish Ministry of Education and Science, research project No.AGL2006-04666/AGR, and by the EU, research project ref. STREP 023120 .

\section{Literature Cited}

Diaz-Espejo, A., Hafidi, B., Fernández, J.E., Palomo, M.J. and Sinoquet, H. 2002. Transpiration and photosynthesis of the olive tree: a model approach. Acta Hort. 586:457-460.

Diaz-Espejo, A., Walcroft, A., Fernández, J.E., Hafidi, B., Palomo, M.J. and Girón I.F. 2006. Modelling photosynthesis in olive leaves under drought conditions. Tree Physiol. 26:1445-1456.

Ennajeh. M., Tounekti, T., Vadel, A., Khemira, H. and Cochard, H. 2008. Water relations and drought-induced embolism in olive (Olea europaea) varieties 'Meski' and 'Chemlali' during severe drought. Tree Physiol. 28:971-976.

Fernández, J.E. 2006. Irrigation Management in Olive. In: Special Seminars and Invited Lectures (T. Caruso, A. Motisi, L. Sebastiani, Eds.), pp. 295-305. OliveBioteq, $2^{\text {nd }}$ International Seminar on Recent Advances in Olive Industry. 5-10 Noviembre 2006. Marsala-Mazara del Vallo, Italia.

Fernández, J.E., Díaz-Espejo, A., Infante, J.M., Durán, P., Palomo, M.J., Chamorro, V., Girón, I.F. and Villagarcía, L. 2006a. Water relations and gas exchange in olive trees under regulated deficit irrigation and partial rootzone drying. Plant Soil 284:273-291.

Fernández, J.E., Durán, P.J., Palomo, M.J., Diaz-Espejo, A. and Chamorro, V. 2006b. Calibration of sap flow estimated by the compensation heat pulse method in olive, plum and range trees: relationships with xylem anatomy. Tree Phyisol. 26:719-728.

Fernández. J.E. and Moreno, F. 1999. Water use by the olive tree. J. Crop Prod. 2:101162.

Fernández, J.E., Moreno, F., Girón, I.F. and Blázquez, O.M. 1997. Stomatal control of water use in olive tree leaves. Plant Soil 190:179-192.

Fernández, J.E., Palomo, M.J., Diaz-Espejo A. and Girón I.F. 2003. Influence of partial soil wetting on water relation parameters of the olive tree. Agronomie 23:545-552.

Green, S.R., Clothier, B.E. and Jardine, B. 2003. Theory and practical application of heatpulse to measure sap flow. Agron. J. 95:1371-1379.

Jones, H.G. 1983. Estimation of an effective soil water potential at the root surface of transpiring plants. Plant Cell Environ. 6:671-674.

Moreno, F., Fernández, J.E., Clothier, B.E. and Green, S.R. 1996. Transpiration and root water uptake by olive trees. Plant Soil 184: 85-96.

Moreshet, S., Cohen, Y., Green, G.C. and Fuchs, M. 1990. The partitioning of hydraulic conductances within mature orange trees. J. Exp. Bot. 41:833-839. 
Nardini, A., Gascó, A., Raimondo, F., Gortan, E., Lo Gullo, M.A., Caruso, T. and Salleo, S. 2006. Is rootstock-induced dwarfing in olive an effect of reduced plant hydraulic efficiency? Tree Physiol. 26:1137-1144.

Pastor, M. (Ed.). 2005. Cultivo del Olivo con Riego Localizado. Coedición Junta de Andalucía, Consejería de Agricultura y Pesca, y Ediciones Mundi-Prensa, 783 pp.

Salleo, S. and Lo Gullo, M.A. 1983. Water transport pathways in nodes and internodes of 1-year-old twigs of Olea europaea L. G. Bot. Ital. 117:63-74.

Tognetti, R., d'Andria, R., Morelli, G. and Alvino, A. 2005. The effect of deficit irrigation on seasonal variations of plant water use in Olea europaea L. Plant Soil 273:139-155.

Tognetti, R., d'Andria, R., Morelli, G., Calandrelli, D. and Fragnito, F. 2004. Irrigation effects on daily and seasonal variations of trunk sap flow and leaf water relations in olive trees. Plant Soil 263:249-264.

\section{Fionres}

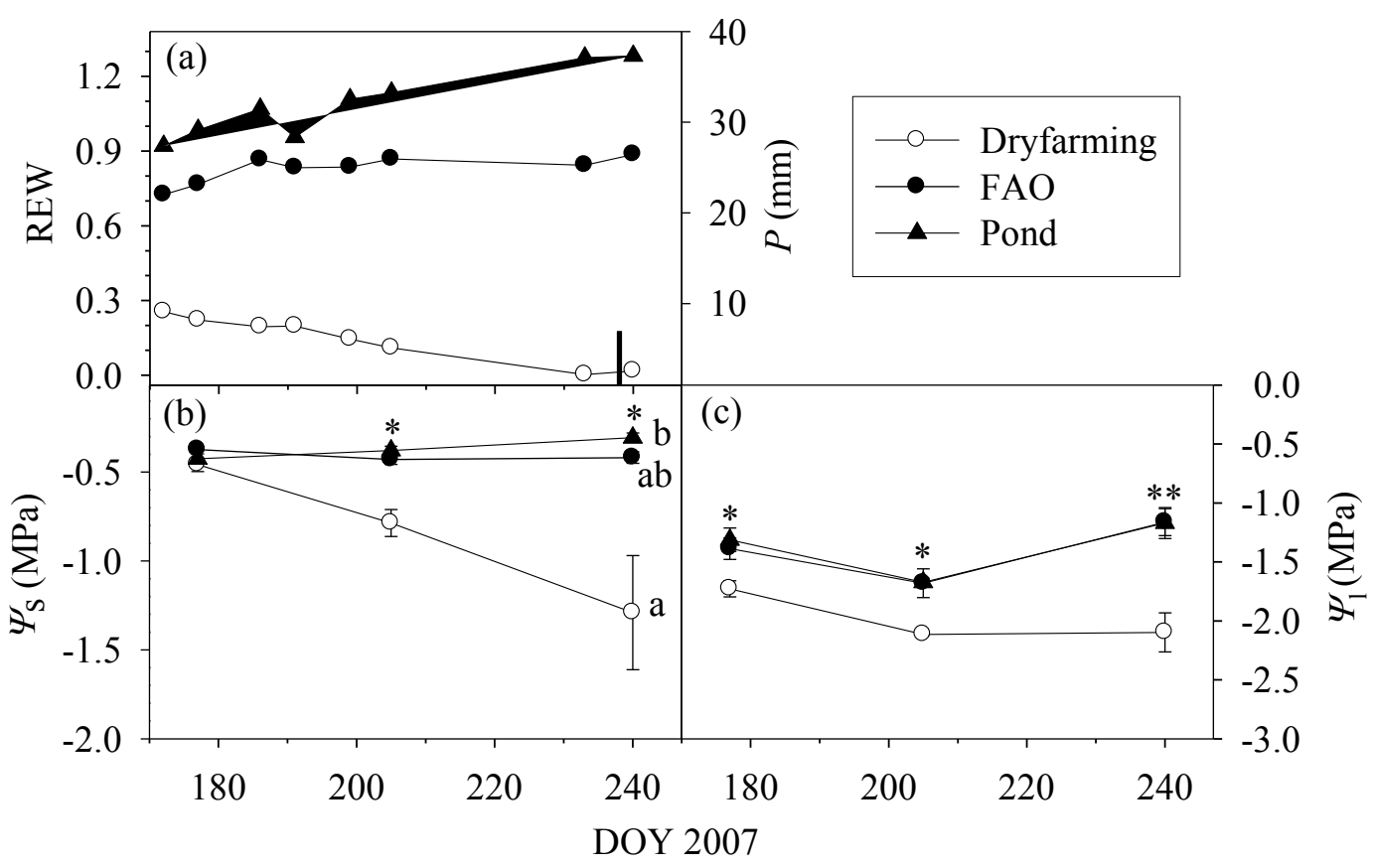




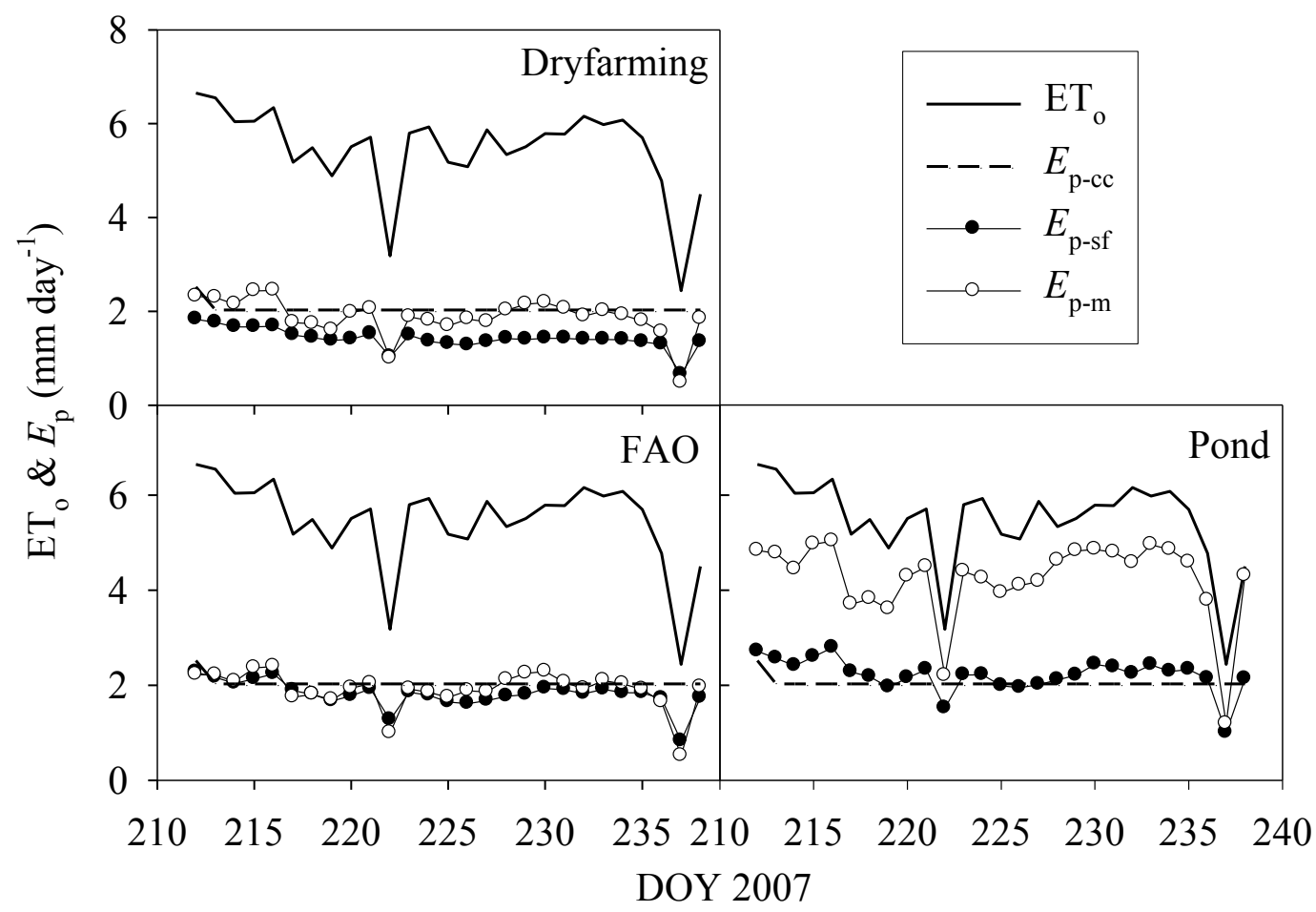



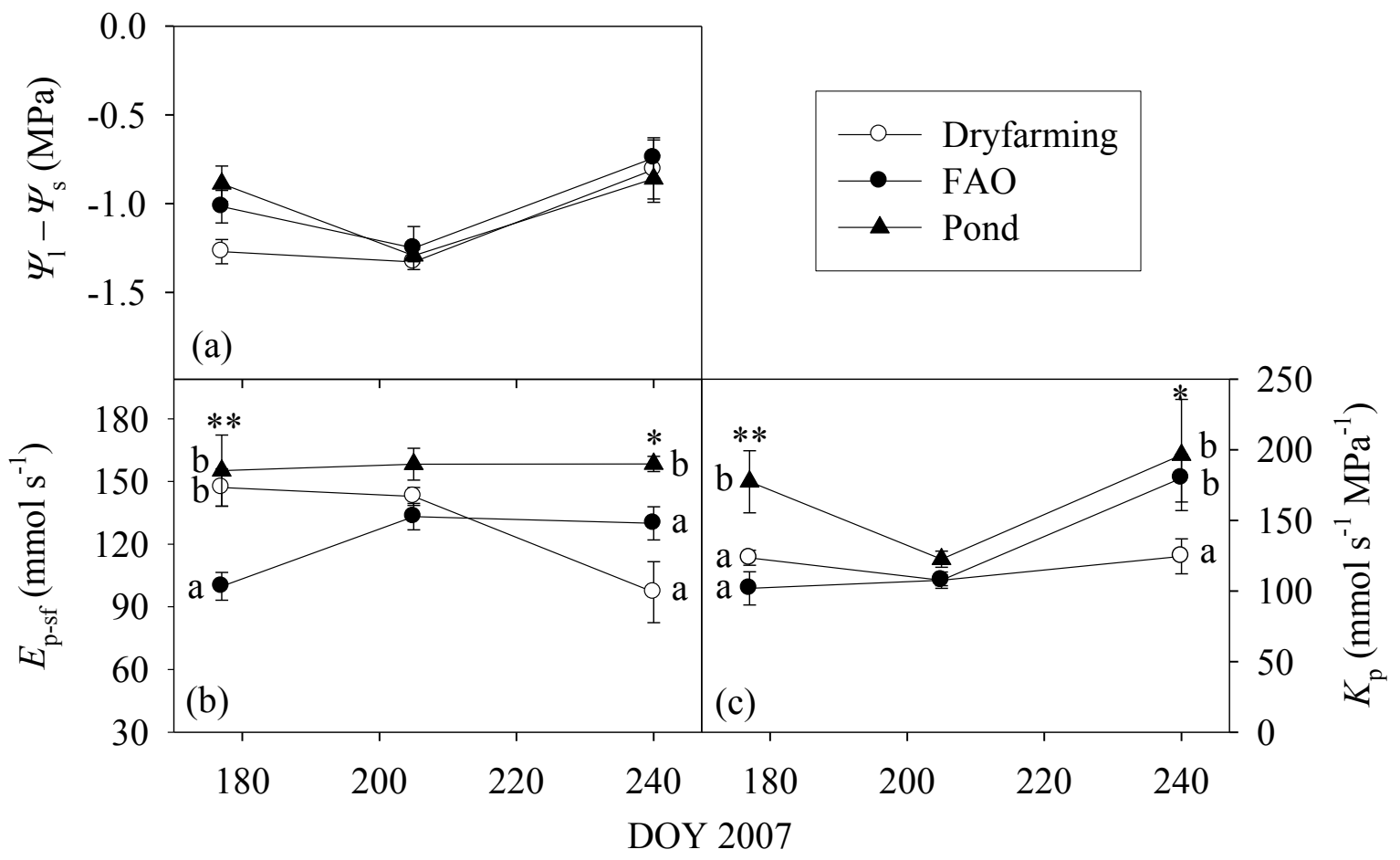